\title{
AIR CLEANING TECHNOLOGIES FOR TUNNELS - HONESTY IS THE BEST POLICY FOR PROTECTING HUMAN HEALTH
}

\author{
A. E. Dix \\ Engineering Department, \\ Visiting Professor of Tokyo City University, Tokyo, Japan
}

\begin{abstract}
Motor Vehicle tunnels capture both direct emission and remobilized particles as well as gasses. These captured particles and gasses must be responsibly managed to ensure risks to human health are mitigated. Active air cleaning technologies which can remove particles and gasses are sometimes used in road tunnels. Passive air dispersal techniques are commonly used. In some rare instances Passive and Active systems are used together. Unfortunately, active air cleaning technologies are often NOT used once a project is approved and operating. In the absence of a passive ventilation strategy - not using the active ventilation system may result in a greater risk of harm to people than if no active air cleaning system was used at all. The best policy for managing the risks to human health from vehicle emissions is to ensure exposure is managed - by whatever method is best in the unique circumstances of each tunnel.
\end{abstract}

Keywords: Tunnels, Ventilation, Risk, Emissions and Environment.

Cite this Article: A. E. Dix, Air Cleaning Technologies for Tunnels - Honesty is the Best Policy for Protecting Human Health. International Journal of Civil Engineering and Technology, 11(1), 2020, 318-328.

http://iaeme.com/Home/issue/IJCIET?Volume=11\&Issue $=1$

\section{INTRODUCTION}

Tunnels provide unique opportunities to create new efficient linkages for travel within cities. These new links improve the environmental efficiency of transportation links by optimising the efficiency of motor vehicle journeys usually resulting in reduced emissions for the equivalent journey without tunnels.[1]

The responsible management of captured internal combustion engine emissions and dusts includes consideration of utilising tunnel air cleaning technologies. The use of tunnel air cleaning technologies is just one of the options for managing internal combustion engine emissions including at source (including filtration and other onboard solutions), changed energy source (e.g. electric) diluting and dispersing the captured internal combustion engine emissions and optimises the route.[2] 


\section{A. E. Dix}

\section{THE HEALTH ISSUES}

All vehicles generate particulates and gases that are known to harm human health.[3] All particles harm human health whether they are artificially or naturally generated.[4][5][6][7][8][9][10][11][12][13]

The best known example of particle generation is emissions from fossil fuel powered internal combustion engines.[14] Other particles are generated by mechanical action of brakes, wheels and even turbulence induced by vehicles. It is now well understood that the exposure of humans to particles generated by internal combustion engines and some gases causes ill health. Originally the particles were regulated in the PM10 range (particles at or less than $10 \mu \mathrm{M}$ (microns)).[15][16][17] As techniques improved to measure the particles regulatory control of PM2.5 (particles at or less than $2.5 \mu \mathrm{M}$ ) and most recently PM1.0.[18][19][20][21][22][23][24][25]

It is also noted in the literature that the composition of these particles can also impact the severity of the risk to human health with diesel derived particulates generally considered more harmful than gasoline derived particulates.[26] Nitrogen dioxide is also recognised as an important cause of adverse health effects.[27][28]

\section{REGULATION}

As a result of the recognition of the adverse impact of internal combustion engine particulates and gases, strict emission standards have been imposed on car registration in most countries forcing manufacturers to substantially reduce the emission rates produced by the engines in their vehicles.[29][30]

In addition, the increasingly high cost of fossil fuels and the coupling of registration fees to engine capacity have driven the adoption of smaller vehicles and engine size and pollution emission rates which likewise has contributed to the reduction in vehicle emissions per kilometre travelled.[31]

These factors have also driven the development and adoption of alternative energy vehicles which either transfer pollution production to centralised power stations or utilise non fossil fuel burning technologies entirely.[32]

During the past 50 years stringent policies on industrial particulate emissions have been introduced in most countries leading to substantial improvements in ambient air quality in many cities.[33][34][35]

Politically, despite general improvements in air quality, respiratory health has emerged as a major issue for the inhabitants of cities.[36] Citizens identify respiratory and cardiovascular good health as a high priority for them in the urban environment[37] and politicians routinely are elected, or gain favour, by implementing pollution reduction measures.[38]

The disconnection between the science and technology of such pollution reduction measures begins by the political process not quantifying the benefits of pollution reduction measure. A pollution reduction measure that draws upon public resources competes with other initiatives that provide health and lifestyle benefits to a community such as hospital funding, price of electricity and waste disposal.[39][40]

Furthermore, there is a difference between reducing the gross amount of pollution and reducing the human exposure to pollution - this is difficult to communicate in a political context. 


\section{DILUTION AND DISPERSION}

In many situations, road tunnels can utilise dilution and dispersion techniques that do not alter the amount of pollution that is produced but ensure people are not exposed to unacceptable levels of risk associated with the vehicle emissions exposure.[41]

The use of dilution and dispersion techniques to control exposure of people to vehicle emissions is well understood and there are no known or reported instances where exhausted tunnel air pollution has been detectable at the surface where people breath. This means that the dilution and dispersion technology when designed and operated correctly to achieve set air quality exposure levels mitigates the risk to health risk to humans of tunnel air emissions.

\section{AIR CLEANING TECHNOLOGIES}

In a number of countries including Japan, China, Italy and Spain air cleaning technologies seek to remove particles from tunnel air before it is discharged to atmosphere. In Japan such systems are used in conjunction with dispersion ventilation technology. In Spain on the M30 project and in the Wan Chai tunnel in Hong Kong the air cleaning technology is used as a substitute for full height dispersion technology.

In Japan the policy of using air cleaning technology is entirely consistent with the removing particulates from cities air that previously was very polluted. In Japan if the air cleaning technology is not used people are still protected from exposure to the particulates and gases as dispersion technology ensures there is no detectable impact. This must be contrasted with Spain's M30 project where a failure to use the air cleaning technology means that particulates and gasses being discharged are not discharged through full height dispersion systems if needed.

The politics of the use of the air cleaning technology in Hong Kong's new road tunnels is even more complicated than Japan because the most recent Wan Chai tunnel ventilation proposed ventilation tower to achieve air quality health objectives would have obstructed the views from some of Hong Kong most expensive harbour view properties.

China has a stated 'blue sky' policy whereby the central government has imposed a raft of air quality objectives as a national priority. While the decision to use particulate removal technology in Hong Kong may have publicly been described as bringing health benefits, as in Spain, the absence of full height dispersion structures means that managing human exposure to unacceptable vehicle pollution levels is dependent upon vehicle emission controls and the air cleaning technology being used and maintained to control the emissions from the tunnels in absolute terms.

In order to maintain transparency of the operation and effectiveness of installed air cleaning technologies in Japan the government provides real time data via the internet on the performance of the air cleaning systems. In Hong Kong and Spain no such transparency has been identified and in Spain there is no public visibility of the tunnel air quality, status of air cleaning system operation or any other parameter. The Spanish M30 project entirely relies upon air cleaning technology to mitigate external health impacts from any instances of poor in-tunnel air quality when they occur.

This means that in Japan the community is 'protected' from the perceived risk from vehicle particulates by both physical dispersion structures and active air filtration (either of which separately could deliver the same outcome). In Hong Kong human exposure is managed solely by the air cleaning technology which must be maintained and operated when necessary. In Spain there is no public means of determining whether the air cleaning system should be operating, if it is operating or even how well it is operating in the event that it is activated. 


\section{A. E. Dix}

\section{STATUS QUO}

A review of technical projects in Wan Chai Bypass tunnel in Hong Kong, Shinjuku tunnels in Japan and the Calle M30 tunnels in Spain reveals that:

a. Tunnel air cleaning technology for the removal of particulates is installed and:

i. operational in the new Shinjuku tunnels in Tokyo

ii. soon operational in Wan Chai tunnel in Hong Kong

iii. has been barely used since installation over the last decade in Spain

b. Tunnel air cleaning technology for the removal of particulates is not yet installed in tunnels in Mainland China but it is likely it will be installed in polluted regions as part of the 'blue sky' policy implementation

c. $\mathrm{NO}_{2}$ removal technology is installed and:

i. operational in the Shinjuku tunnels in Tokyo

ii. not yet operational in the Wan Chai tunnel in Hong Kong

iii. has been barely used over the last 10 years in Spain

d. NOx removal technology is installed and:

i. operational in the Shinjuku tunnels in Tokyo

ii. has been barely used over the last 10 years in Spain

e. Dispersion stacks:

i. are constructed and used to disperse tunnel emissions in the Shinjuku tunnels of Japan

ii. are not installed in the Wan Chai tunnel in Hong Kong

iii. are not installed in Madrid, Spain on the Calle M30 project

f. In Hong Kong, Japan, Spain and increasingly China the motor vehicle fleet is rapidly renewing with stringent vehicle emission controls imposed and enforced

In Hong Kong the main driver for the use of air cleaning technology was apparently the removal of the vertical ventilation structures from the skyline as they are perceived to be an unwelcome obstruction of the extremely valuable Hong Kong Island real estate view to the harbour.

China is embracing an aggressive 'blue skies' policy which includes forcibly shutting industry during periods of poor weather (typically autumn and winter for extensive periods of time) imposing increasingly strict emission controls, prohibiting the use of aged vehicles, accelerating the use of alternative fuel vehicles and active tree planting programs.

While high proportions (almost all) $\mathrm{NO}_{2}$ is presumed removed from the tunnel air by the air cleaning technology in Hong Kong, the $\mathrm{NO}_{2}$ represents only a small proportion of the $\mathrm{NOx}$ being discharged.

By contrast the Shinjuku tunnels in Tokyo use two competing technologies, both of which convert $\mathrm{NOx}$ to $\mathrm{NO}_{2}$ for subsequent $\mathrm{NO}_{2}$ removal by the tunnel air cleaning plant and thereby substantially reduce the discharge of $\mathrm{NO}_{2}$ to the environment.

On the M30 Project in Spain the systems are not used much and are at best used during a very small proportion of the day. In Spain the tunnels are mostly operated with full portal emission regime and no regular use of the active air filtration systems.

In each instance, the use of the technology for air cleaning has not been accompanied by effective opposition to the projects by the public or surrounding landowners'. In Spain and Hong Kong there was vocal opposition to the use of tall ventilation / dispersion towers, while in Tokyo the community wanted towers and air cleaning. 
Whilst it can be concluded that there is considerable experience for particulate removal systems (ESP and mechanical) the installation of gas cleaning techniques (for $\mathrm{NO}_{2}$ and $\mathrm{NOx}$ ) has only been trialled in a handful of tunnels.

\section{CONSEQUENTIAL ISSUES}

The use of active air cleaning technologies that remove particles and problem gases use energy, create waste streams and require maintenance. This means that operationally the active air cleaning technologies require ongoing commitment and investment to maintain their functionality. For this reason, a decision to use these technologies not only impacts the availability of public resources at the time of construction, it also requires an ongoing operational commitment for so long as the particle and problem gas issues remain.

For example, the denitrification plants in both Spain and Japan require special expertise to renew and maintain the equipment and to harvest the intercepted oxides of nitrogen. In each case substantial "offsite" de-NOx infrastructure and expertise is required to operate and maintain the equipment.

The operational costs of the air cleaning technologies including waste disposal, labour, maintenance and spare parts for technologies are not available in the public domain.

In no jurisdiction is there any published information on the relationship between particles and ill health in the context of the residual or background particle load. In each jurisdiction justification for the technology is expressed in terms of amounts of particles and gases removed from tunnel air without quantifying the benefit.

In the future it is conceivable that the entire vehicle fleet will be propelled by alternative fuel vehicles that do not produce any combustion products. These vehicles will still produce particles and perhaps even oxides of nitrogen (high energy electricity).

The tyres and brakes will also produce particles from non internal combustion powered vehicles. Should there be no vehicles at all, background natural particles such as salt from the sea will also pose a health issue for humans. The cost of removing particles and gases should be balanced against the benefit received.

\section{COMMERCIAL INTERESTS}

There are strong commercial interests for the adoption of air cleaning technologies in road tunnels. Most obviously vendors of equipment and ongoing maintenance and service, waste disposal and monitoring are able to provide their engineering solutions which demonstrably reduce the amount of particles in air - for a fee.

Less obviously it is in the communities' interest to proceed with tunnel projects because they generate wealth and income during construction and tunnels invigorate and make more efficient the activities the tunnels serve. From a government perspective the costs of active air cleaning technologies may be in insignificant compared with the mitigation or elimination of project delay or project cancellation risks. In this context the burden of air cleaning technologies on limited public financial resources is considered minor in the broader political economic context because it pacifies local community objection to projects and facilitates more rapid project delivery. This fact is recognised by the peak association of road authorities in the world publication on air cleaning technologies where it is noted that achieving project approval is a legitimate justification for spending money on air cleaning technology - which by normal scientific or engineering measures may be unnecessary and not cost effective for a specific project.[42][43] 


\section{A. E. Dix}

\section{CASE STUDIES}

\subsection{Japan}

In Japan air cleaning technologies are routinely used in highly congested, heavily polluted urban environments for both the removal of particles and in some instances the removal of NOx. In such environments there may be a net environmental benefit.[44]

Improvements in the effectiveness of particle removal appear to be facilitating the more sustainable use of NOx (removal technologies) specifically those involving activated carbon (albeit with a range of exotic trade names) and other adsorbent and absorbent technologies.

In the new Shinjuku line project in Tokyo both particle removal and NOx removal technologies are being installed and have been observed.

In the case of air cleaning technologies advances in the performance of electrostatic precipitators (in terms of efficiency and reliability) are leading to the potentially viable use of denitrification technologies. The performance and long term reliability of these denitrification technologies appears promising especially given the long guarantees (20 years) being offered by several Japanese companies.
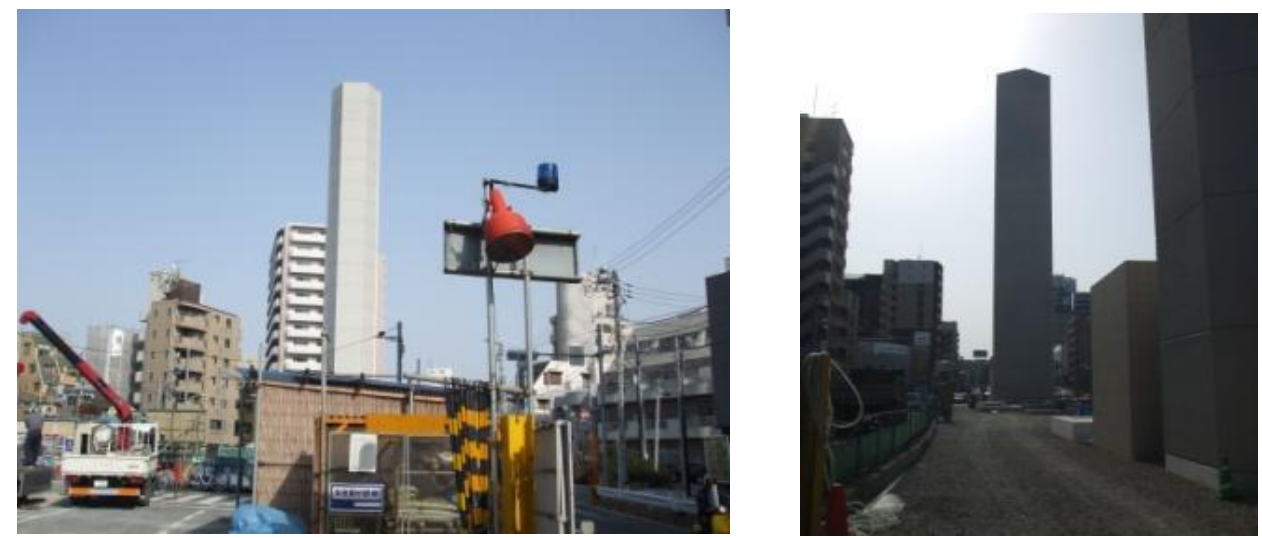

Figure $1 \& 2$ Ventilation towers along Shinjuku route. Note spatial relationship with accommodation towers

\subsection{Findings from Japan}

The Ministry of the Environment of the Government of Japan have strict environmental quality standards.[45] Japan transparently regularly update report their air quality website.[46] Some of the monitoring stations are installed beside major roads or intersections to determine the influence of automobile emissions. Areas of extreme pollution can be viewed within hours via the website.[47]

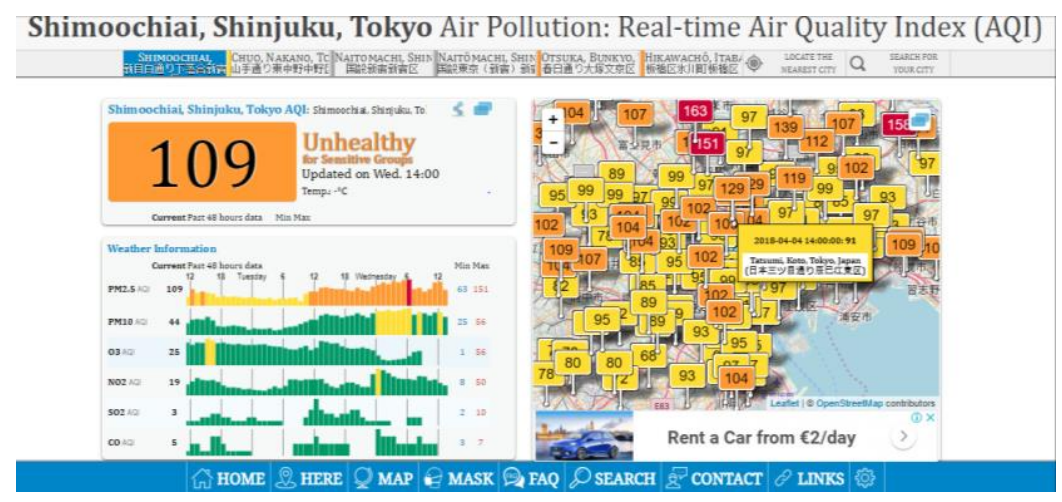

Figure 3 Illustrates the air quality at 16:42 on 4 April 2018[48] 
Japan has the highest number of installations of ESP and $\mathrm{NO}_{2}$ air cleaning technologies in road tunnels in the world. By 2009 installations of ESP (not $\mathrm{NO}_{2}$ or NOx) technology was reportedly 52 tunnels[49], it is higher today.

Japan views air quality very seriously. Principally the air quality of the general airshed is regulated by stringent controls on emissions from industry and motor vehicles with internal combustion engines. The use of particle removal technologies in Japanese tunnels is, compared to other countries, common. Principally these installations are made in order to protect the air quality outside tunnel portals, especially where the roads are used principally by heavy goods vehicles and other diesel powered vehicles. This is analogous to the installation of air cleaning technologies in Monte Blanc in France and also the Chinbu Tunnel in South Korea where high truck numbers drive local community discontent. There is a strong correlation between the installation of particle removal technologies and roads with high concentrations of freight and other heavy vehicles in Japan. The initial impetus for the installation of these technologies in Japan was dissatisfaction by local residents in highly concentrated urban developments proximate to the tunnel portals and other emission points. Damage to fruit and laundry from diesel vehicle emission was common.

\subsection{China}

\subsubsection{Hong Kong - Wan Chai Bypass}

Hong Kong Island experiences extreme traffic congestion. A road tunnel to relieve road congestion along the foreshore has been proposed for at least 30 years.

The government were faced with severe issues in getting approval for the Wan Chai tunnel as it runs along the reclaimed, foreshore, area at the front of the coastline of the island of Hong Kong. There were severe concerns raised by the community about this tunnel. The tunnel is 3.4 kilometres long.

Initially the environmental agency wanted particles removed from the tunnel air but subsequently they changed their requirements to include $\mathrm{NO}_{2}$ removal. In 2013 an Environmental Permit to Operate was approved:

'An Air Purification System (APS), including an electrostatic precipitator system (ESP), with removal efficiency of at least $80 \%$ of dust to reduce the level of respirable suspended particulates (RSPS), and a NO2 removal system (De-NO2 Filter) with removal efficiency of at least $80 \%$ for NO2, shall be adopted to improve the air quality before discharging to the atmosphere via the WVB, MVB and EVB and its vent shaft.'

The Air Purification System is to be a two stage process: a. Stage 1 - Electrostatic Precipitator to remove respirable suspended particles, and b. Stage 2 - De-Nitrification (De$\mathrm{NO}_{2}$ ) Filter to remove $\mathrm{NO}_{2}$.

The Wan Chai air cleaning technology is promoted on the basis of more than $80 \%$ reduction in $\mathrm{NO}_{2}$.[50] An 80\% removal of $\mathrm{NO}_{2}$ is not an $80 \%$ removal of NOx. NOx converts to $\mathrm{NO}_{2}$ in the presence of an oxidising agents such as ozone or UV light. This means that $\mathrm{NO}_{2}$ will be generated outside the tunnel after it is emitted to the atmosphere.

By using the air cleaning technology, projects justify the reduction in the height of the ventilation dispersion towers. The advantage for neighbours is that views are protected and there is no visual cue that air from a road tunnel is being emitted.

Air cleaning equipment in Hong Kong is designed to remove particles and extract a high proportion of $\mathrm{NO}_{2}$ from large volumes of air - in the order of up to $650 \mathrm{~m}^{3} / \mathrm{s}$ per ventilation station, making this installation the largest on earth. This design is used to eliminate the need for tall ventilation dispersion structures and thereby protects property values along Hong Kong Islands foreshore and disguises the tunnel ventilation structures. 


\section{A. E. Dix}

The project design relies upon high removal rates of $\mathrm{NO}_{2}$ although this represents a small proportion of the total oxides of nitrogen discharge from the tunnel which, later, outside the tunnel (under the influence of ozone and ultraviolet radiation) converts to $\mathrm{NO}_{2}$.

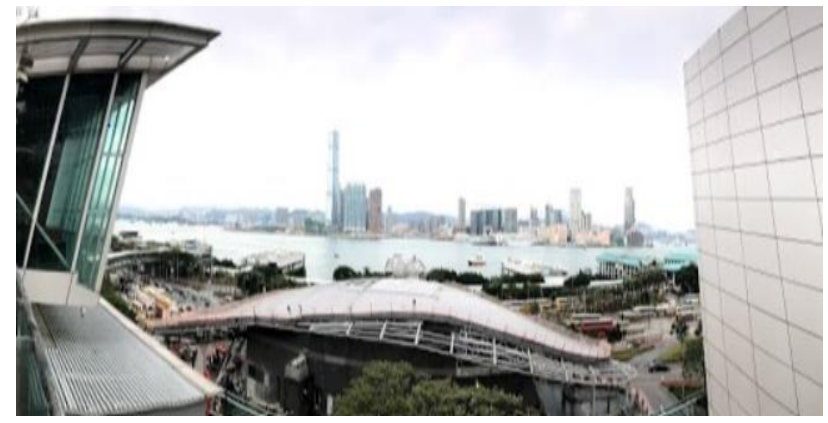

Figure 4 Ventilation Structure

The ventilation structure is the convex, low rise building in the foreground of Figure 4 . The use of air cleaning technologies is used to justify no stack higher than the ventilation building.

The air quality in Hong Kong is improved from 20 years ago. This is directly attributable to a reduction in Hong Kong manufacturing, air pollution reforms in mainland China under the 'Blue Sky' policy, and a remarkable modernisation of the vehicle fleet. By way of illustration Hong Kong cars were observed to consist of a high proportion of Tesla, BMW, Lexus and Toyota electric and hybrid vehicles.

\subsection{Spain}

\subsubsection{Calle M30 Project, Madrid}

The Madrid Calle M30 project was the most advance urban road tunnel in the world in 2008. Before the Calle M30 tunnel project was completed air quality in Madrid was regularly poor. Today most of the air cleaning plants are not routinely used. This suggests air quality has improved so much that use of the air cleaning technology is no longer required. In substance the massive M30 is being operated as a 100\% portal emission system.

\section{CONCLUSIONS}

Decisions about the prioritisation and use of scientific and engineering based infrastructure are not simply based upon the technical merits of the proposal. Instead a range of complex political factors are taken into account by decisions makes in order to achieve broader social objectives.

Active Tunnel air cleaning technologies can be used to remove particles and some gasses harmful to human health. Such an approach should only be used where the health benefits can be demonstrated to represent good value. Such technologies, when used, must not result in adversely impacting the medium to long term risks to human health and environment performance of a tunnel by compromising the passive particle and gas dispersal aspects of the tunnel design.

There is evidence that subsequent to approval to operate tunnels with active air cleaning technologies many tunnels air cleaning systems are not used and maintained as designed or often at all.

While it is understandable that project proponents may include air cleaning as a means of mitigating approvals risk and community acceptance of new road tunnels, it is not acceptable 
to compromise community health by subsequently stopping system operation without public disclosure as to the circumstances of such operational changes.

Protection of human health from the risks posed by vehicle emissions from tunnels is a potentially serious issue which must be dealt with professionally on an ongoing basis, not just cynically by installing active air cleaning technologies to gain public acceptance and project approvals.

\section{REFERENCES}

[1] Roads and Maritime Services: Fact Sheet https://www.rms.nsw.gov.au/documents/projects/sydney-north/western-harbour-tunnelbeaches-link/beaches-link-project-update.pdf

[2] Longley. I., Coulson, G., Olivares. G. Guidance for the Management of Air Quality in Road tunnels in New Zealand https://www.nzta.govt.nz/assets/resources/road-tunnel-airquality/docs/air-quality-tunnels-guidance.pdf

[3] Utell, M.J., Warren, J., \& Sawyer. R.F., 'Public Health Risks from Motor Vehicle Emissions', Departments of Medicine and Environmental Medicine, Annual. Rev. Public Health. 1994. 15, pp.157-78; May 1994

[4] Dockery, D.W., Pope, C.A., 'Acute respiratory effects of particulate air pollution'. Annual. Review of Public Health, 15, pp.107-132; May 1994

[5] Pant, P \& Harrison, RM 2013, 'Estimation of the contribution of road traffic emissions to particulate matter concentrations from field measurements: A review', Atmospheric Environment, 77, pp.78-97.

[6] Hoek, G., et al., 'Association between PM10 and decrements in peak expiratory flow rates in children: Reanalysis of data from five panel studies.' The European respiratory journal: official journal of the European Society for Clinical Respiratory Physiology. 1998 Journal 11(6). pp.1307-11.

[7] Van Vliet P., et al., 'Motor vehicle exhaust and chronic respiratory symptoms in children living near freeways.' Environ. Res.74, (2), August 1997 pp.122-132

[8] Medina S., et al., 'Air pollution and doctors' house calls: results from the ERPURS system for monitoring the effects of air pollution on public health in greater Paris, France, 19911995.' Environ. Res. 75, (1), October 1997 pp.73-84

[9] Hajat S., et al., 'Association of air pollution with daily GP consultations for asthma and other lower respiratory conditions in London.', Thorax 1999: 54: pp.597-605

[10] Carter J. D., Ghio A. J., Samet J. M., Devlin R. B., 'Cytokine production by human airway epithelial cells after exposure to an air pollution particle is metal-dependent.' Toxicology \& Applied Pharmacology. 146, (2), October 1997 pp.180-188

[11] Donaldson K, MacNee W. 'The mechanism of lung injury caused by PM10' In Air Pollution and Health Editors Hester RE, Harrison RM The Royal Society of Chemistry [Issues in Environmental Science and Technology, 10; 1998. pp. 21-32

[12] Peters A., Doring A., Wichmann H. E., Koenig W. 'Increased plasma viscosity during an air pollution episode: a link to mortality?' The Lancet 349(9065), pp.1582-1587

[13] Roemer W., et al., 'The PEACE project: general discussion.' European Respiratory Review 8, 1998 pp.125-130

[14] Shuvashish, K., and Stone, E.A., 'Composition and sources of fine particulate matter across urban and rural sites in the Midwestern United States', Environmental Science. Processes \& Impacts 16(6) 2014: pp.1360-70

[15] Priemus, H., and Schutte-Postma, E., 'Notes on the particulate matter standards in the European Union and the Netherlands' International journal of environmental research and public health 6(3) 2009: pp.1155-73 
[16] Gilmour, P S et al. 'Adverse health effects of PM10 particles: involvement of iron in generation of hydroxyl radical', Occupational and Environmental Medicine 53,(12) 1996: pp.817-22

[17] Kennedy T., et al., 'Copper-dependent inflammation and nuclear factor- $\kappa B$ activation by particulate air pollution'. American Journal of Respiratory Cell and Molecular Biology, 19, (3), 1.9.1998, pp.366-378

[18] Mazzarellaa, G., et al., 'Environmental Pollution Inflammatory effects on human lung epithelial cells after exposure to diesel exhaust micron sub particles (PM1.0) and pollen allergens', Environmental Pollution 161, February 2012, pp. 64-69

[19] Dockery D. W., \& Pope C. A. "Acute respiratory effects of particulate air pollution." Annual Review Public Health, 15, May 1994, pp.107-132

[20] Seaton A., MacNee W., Donaldson K., 'Particulate air pollution and acute health effects' The Lancet 345(8943), 21.1.199 pp.176-178

[21] Ferin J., et al., 'Pulmonary Retention of ultrafine and fine particles in rats' American Journal of respiratory Cell and Monecular Biology, 6(5), 1.5.1992, pp.535-42

[22] Stone V., et al., 'The role of oxidative stress in the prolonged inhibitory effect of ultrafine carbon black on epithelial cell function' Toxicology In Vitro, 12(6), 1998, pp.649-659

[23] Pekkeanen J., et al., 'Effects of ultrafine and fine particles in urban air on peak expiratory flow among children with asthmatic symptoms', Environmental Research Journal, February 1997, 71(1); pp.24-33

[24] Monn C., Becker S., 'Cytotoxicity and induction of proinflammatory cytokines from human monocytes exposed to fine (PM2.5) and coarse particles (PM10-2.5) in outdoor and indoor air.' Toxicology and Applied Pharmacology, 155(3), April 1999, pp.245-252

[25] Pope C. A., et al., 'Oxygen saturation, pulse rate, and particulate air pollution: a daily time-series panel study.' American Journal of Respiratory and Critical Care Medicine 159, (2), 1.2.1999, pp.365-372

[26] HEI Diesel Epidemiology Panel. 2015. 'Diesel Emissions and Lung Cancer: An Evaluation of Recent Epidemiological Evidence for Quantitative Risk Assessment' Special Report 19. Boston, MA: Health Effects Institute. November 2015

[27] Sunyer J., 'Nitrogen dioxide: an unimportant cause of health effects?' European Respiratory Journal, Rev.8, 1998, pp.139-140

[28] Speizer F. E., et al., 'Respiratory disease rates and pulmonary function in children associated with NO2 exposure' American Review of respiratory Disease, 121, January 1,1980

[29] Perry, R., \& Gee, I.L., 'Vehicle Emissions and Effects on Air Quality: Indoors and Outdoors', Journal of Indoor and Built Environment, 3 (4), pp. 224-236 July 1, 1994

[30] Schwartz J., 'Air pollution and daily mortality: a review and meta analysis', Environmental Research 64, (1), January 1994, pp.36-52

[31] Virley, S., 'Transport Policy The effect of fuel price increases on road transport CO2 emissions', Transport Policy, United Kingdom, 1, (1), October 1993, Pages 43-48

[32] Cornell, Ryan P. 2017. 'The Environmental Benefits of Electric Vehicles as a Function of Renewable Energy'. Master's thesis, Harvard Extension School.

[33] Lucas R.F., et al., 'Evaluating the effectiveness of air quality regulations: A review of accountability studies and frameworks', Journal of the Air \& Waste Management Association, 2017, Vol.67(2), pp.144-172

[34] Muller, C.O., Henry Yu., Zhu, B., 2015 'Ambient Air Quality in China: The Impact of Particulate and Gaseous Pollutants on IAQ', Procedia Engineering Journal, 121, 2015, pp.582-589

[35] Commonwealth of Australia., (2015): National Environment Protection (Ambient Air Quality) Measure https://www.legislation.gov.au/Details/F2016C00215 
Air Cleaning Technologies for Tunnels - Honesty is the Best Policy for Protecting Human Health

[36] Kelly FJ, Fussell JC. Air pollution and public health: emerging hazards and improved understanding of risk. Environ Geochem Health. 2015;37(4):631-649. doi:10.1007/s10653-015-9720-1

[37] Newby, D.E., et al., 'Expert position paper on air pollution and cardiovascular disease' European Heart Journal, 36, (2), 7 January 2015, pp. 83-93

[38] Brown, P., et al., 'Clearing the Air and Breathing Freely: The Health Politics of Air Pollution and Asthma' International Journal of Health Services, 34, (1), January 1, 2004

[39] Woods, M., et al., 'Decision support for risk prioritisation of environmental health hazards in a UK city', Environmental Health. 2016, 15 (Suppl 1) :S29

[40] https://www.scribd.com/document/209308615/Balancing-Environment-Benefits-V22010-Katatani-Dix

[41] Capon A, Sheppeard V, Irvine K, Jalaludin B, Staff M, et al. (2008) Investigating health effects in a community surrounding a road tunnel stack - a cross sectional study. Environmental Health 7: 10.

[42] PIARC Technical Committee C.4 Road Tunnel Operation, 'Road Tunnels: Vehicle emissions and air demand for ventilation', Environment / Road Tunnel Operations., 2012 PIARC Ref: 2012R05EN ISBN : 978-2-84060-269-5 p87

[43] Technical Committee 3.3 Road Tunnel Operation, 'Road tunnels: a guide to optimising the air quality impact upon the environment' 2008, Environment / Road Tunnel Operations PIARC Ref: 2008R04EN ISBN : 2-84060-204-0 p179

[44] Katatani, A., Dix, A., 2011 "Ventilation and Exhaust Purification of Motor Vehicle Tunnels in Japan" BHR Group, $14^{\text {th }}$ International Symposium on Aerodynamics and Ventilation of Tunnels, Dundee, Scotland

[45] https://www.env.go.jp/en/air/aq/aq.html

[46] http://www.kankyo.metro.tokyo.jp/en/automobile/monitoring.html

[47] http://www.taiki.kankyo.metro.tokyo.jp/cgi-bin/bunpu1/p101.cgi

[48] http://aqicn.org/city/japan/shinjukuku/shinmejirodorishimoochiai/

[49] Brandt. R., Riess. I., 2009 "Possibilities and limitations of tunnel-air filtration and portalflow extractions" BHR Group ISAAVVT 2009 New Brunswick

[50] http://www.cwb-hyd.hk/download/documents/en/Newsletter\%20No28_final.pdf 